\title{
FinTech in Russia under circumstances of IT technologies development: development challenges and solutions
}

\author{
M.A. Ponomareva ${ }^{1, *}$, D.V. Karpukhin ${ }^{1}$, and A.N. Stolyarova ${ }^{2}$ \\ ${ }^{1}$ Financial University under the Government of the Russian Federation, 49 Leningradsky Prospekt, \\ 125993, Moscow, Russia \\ ${ }^{2}$ State University of Humanities and Social Studies, 30, Zelyonaya street, 140410, Kolomna, Moscow \\ Region
}

\begin{abstract}
In modern Russia, the FinTech is relevant to the development of the financial segment of the economy. The Government evaluates the prospects of development of artificial intelligence technology, blockchain, big data in the area of budget, tax, customs and other relations by now. However, the development of the FinTech in Russia faces many problems. First of all, these is the absence of digital infrastructure for mining cryptocurrency, issues related to information security, the potential risks of illegal non-personalized transactions through the blockchain technology. It is necessary to analyze the content of the discovered institutional problems and to determine the ways to resolve them. The significant role in overcoming the difficulties is assigned to the Federal Law "About the Digital Financial Assets", which shall enter into force on the 1st of January 2021. Besides the foreign experience in overcoming the difficulties related to the utilization of FinTech is particularly valuable for Russia to solve the identified issues effectively.
\end{abstract}

\section{Introduction}

By now the Russian Federation is headed for the official recognition of the FinTech at the state level, although some institutional FinTech exist in the Russian Federation within the last few years. Almost all large Russian banks have departments, which are aimed at the FinTeh, and can be given as examples. "Alfa Bank", "Gazprombank" and "Binbank" have the dedicated Digital Divisions.

At present moment there is a tendency, when banks, in one or another way, segregate their digital "daughter" or some banks are founded precisely in order to deal with the FinTech only. At the same time, banks have to be prepared to assign a lot of the main traditional functions to the traditional partner organizations operating in the area of FinTeh, meanwhile they have to retain their values (history, stability etc.) and their brand along with the support for organizational stability and security.

\footnotetext{
*Corresponding author: Ponomareva-m@mail.ru
} 
Practical usage of a number of financial technologies has proved, that the usefulness in daily activities and the easy utilization for the end user, likewise the visibility and almost the immediate information about the requested result, have influenced the rapid implementation of them in real life. The efficiency got from the usage prevails over all other factors, including risks in the event of a choice between traditional banking services and use of the FinTech. Currently we have a paradoxical situation, where the convenience and utility are the most important and influential features in terms of usage, what led to the application of the financial technologies, despite the absence of the state regulation. However, security and data privacy require institutional aspect [1].

On the other hand, the risk exists, that the FinTech innovation might be restricted by the legal regulation, which will be excessively focused on security and stability in order to prevent criminal actions, and will avoid the opportunities of Internet use in the financial sector, as well, will ignore the interests of society and technological progress. Several countries of the European Union pursued such policy in the earliest 2010s [2], however they had to change the vector of the legal influence and developed the regulatory approaches, which facilitate innovation and solving related issues.

Based on the foregoing, in order to eliminate the appearance of the applications having not been tested and not matching the security requirements on the market, it is necessary to regulate the interaction between the governments, the centers of global development, technology companies and banks on the matter of all new technologies promotion. At the same time, the regulation of the FinTech should not be excessively prohibited, meet the principles of reasonable sufficiency (avoid excessive regulation), in order to simplify the promotion of innovations in the financial sector, though such regulation is mandatory to be aimed at reducing the potential risks as for consumers as for banks and FinTech startups. As well, it should be focused on the protection of consumers' interests. The strategy of regulatory system, based on the balance and stability principles of the financial system from one side, and easy access to financial services provided by innovations from other side, must be build and adopted to current economic environment. The harmonious combination of state and corporations' interests is the best way to overcome the institutional problems of the information security associated with the usage of the FinTech [3].

The next institutional problem of the FinTech development in Russia is the problem of determining the priority direction. Currently two FinTech directions are formed, such as bank and stock technologies. [4] Various FinTech startups are developed inside them independently. In the Russian Federation there is no consensus on what innovations should be regulated first. In the opinion of the Expert Council on legislative support of financial technologies development in the Russian Federation at the State Duma Committee on Financial Market, the attention should be paid to the regulation of blockchain technology and cryptocurrency usage in the first place. By the way it does not exclude the opportunity to launch pilot projects related to the so-called ICO [5] (Initial Coin Offering - initial placement of tokens, what means the issue of the cryptographic substitute for money by any party, if there is a shortage of cash, the so-called tokens intended to be used as payment for trading floor services in the future).

Identified problems are directly linked to the issue of cryptocurrency mining (extraction) in Russia. Regardless of what FinTech direction will be chosen in Russia, it should be stated, that the modern competitive digital infrastructure, which is capable to provide its own digital issue of cryptocurrency, does not exist in Russia. As a result, the political risks appear, which are associated with the dependence of FinTech development in Russia from mining of cryptocurrency, such as bitcoin, issued by leading international financial and computer corporations. The creation of the national financial digital assets and digital currency, what must become the means of payment, is exactly one of the purposes for FinTech legalization in Russia. 
In our view, the resolution of these institutional problems is sitting in two planes. The first is to develop a strategy for regulation of FinTeh in Russia, which should have the following ideology. The general principles of FinTech development in the Russian Federation should be ensured by the Federal law and their execution is allowed only in the form of a pilot project considering the compliance with the requirements of information and public security. Then the regulations, standards and protocols enforced by secondary acts of the Government, relevant ministries and the Central Bank should be developed for wellproven financial technologies. At the same time, a number of financial and economic measures related to the creation of its own competitive infrastructure and aimed at mining of cryptocurrency in Russia should be implemented.

\section{Business areas of application of the blockchain}

One of the major segments of the FinTech is blockchain. Current growth of financial technologies is the subject of attention for many players in the financial sector. Many of them are examining the application of blockchain across multiple business directions. During last years the global investments in the financial technologies (FinTech) exceeded the amount of 24 billion dollars in 2016 [6]. It is expected that such a revolutionary development of FinTech will impact on the financial markets significantly by means of insertion in the banking services, payment services, insurance, assets management and the stock exchanges as well. Many researchers and practicians consider blockchain technology as a main technology, which will contribute to the FinTech development.

Initially blockchain was designed for the Bitcoin, however it should not be associated only with cryptocurrency, as this technology has a great potential to be implemented in several financial areas, including payment systems and market infrastructure [7]. Blockchain is a process of continuous growth of chains of blocks, in which all accomplished transactions are recorded. The database copies or parts of it are stored on multiple computers at the same time and synchronized in accordance with the formal rules of building the chain of blocks. First of all, this technology is a technology of equal users, so it does contain the centralized start and all of its users have an equal status and opportunities. Secondly, blockchain is not personified. On the other hand, this financial technology ensures disclosure and transparency of transactions, all participants of the system have an opportunity to check the history of their execution. As startups as large financial and technology companies are working on the variances of usage of the global distributed cryptographically secured open data register on all economic area.

The benefits, associated with the implementation of blockchain technology, including intermediaries, are the highest data quality, reliability and the absence of key points, that might be vulnerable to hacker attacks. Thus, the usage of blockchain for transactions is expected to make this transaction to become cheaper, faster but also more reliable and transparent, as it is processed in the integer-valued data transmission system. The obvious technical advantages of an open system may be used to ensure a safe and ordered virtual environment for financial infrastructure.

In the Russian Federation such companies as VTB and Sberbank show an interest to this technology. The cellular operator "MegaFon" issued bonds in amount of 500 million rubles, on which the payments will be made by means of blockchain technology. In 2018 the blockchain technology was tested to verify the data of the Unified State Registry of Real Estate (EGRN) in Moscow. The payment systems VISA, Mastercard, Unionpay and SWIFT were interested in the usage of this technology in different degrees. 


\section{Problems in technology and ways to solve them}

At the same time aside to positive effect the blockchain technology has as separate single as system failures. The scientists consider, that the main serious problem of blockchain technology is its possibility to simplify the usage of so called "smart contracts", what means digital figured out contracts, in which execution of contractual terms occurs automatically without human involvement. [8]. This is done by the settlement of program lines, which perform the procedures in accordance with contractual obligations between parties (such as periodic coupons payments on bonds or execution of derivative contract) independently without intermediaries' involvement (such as bank or central contractor). Smart contracts could improve the compliance with contract terms and automate office work, that accordingly will exclude the human factor in the performance of these processes, will reduce mistakes and formal grounds for legal disputes and will minimize administrative costs as well. [9] However, the legislation of most countries considers such transactions as illegal.

To confirm the transfer of funds from one bank to another are used verification centers. They confirm the fact of payment, which cannot be disputed under any circumstances. This increases the cost and slows down the execution of payments. Blockchain confirms the fact of payment algorithmically and there is no need to use a third-party mediator to verify the authenticity of the payment. This speeds up and reduces the cost payments execution. [10] However, this technology requires a legislative fastening.

For the widespread implementation of blockchain technology many obstacles need to be removed in order to ensure all the benefits of this technology. In terms of market application of blockchain, it is necessary to check and to test the technology for the matter of efficiency and safety. There is a sustainable opinion, that the operations performed by means of blockchain technology are safe, and it is not possible to distort, destroy and replace the information fixed in it. However, this can be considered as an error. Just an insignificant market share owned by cryptocurrency does not attract cybercriminals to develop technologies to overcome it. Although the cases of criminal influence on blockchain startups are already widely known. So, based on the confirmed data of CoinDesk resource, while ICO of Israeli blockchain startup CoinDash unknown hackers spoofed the address of the purse for collections of investments on the company's website. As a result, 7.5 million dollars were stolen by criminals [11]. The experts of Kaspersky Laboratory predict the vulnerability of systems built on blockchain technology up to $51 \%$ of attacks at the moment, when someone with a high processing power comes into the system and becomes the main player being able to overwrite the history of transactions, as he desires. [12]

Another issue of blockchain, which must be resolved is the confidentiality of information and protection of privacy. Ideally all data must be encrypted in the blockchain. In comparison to bitcoin the user will not be able to review the data placed into blockchain. This is because many companies do not want to disclose the contents certified by blockchain, like many citizens, protecting their privacy as well. Therefore, data protection and confidentiality are key factors for blockchain.

Besides the classical blockchain technology is very energy and resource consuming one. As an example, after 2 years from startup and in half a year of active usage the FinTech of Ethereum network contains already 200 gigabytes of data in blockchain. This volume must be stored by each user of the system. For comparison, it is the capacity of the top mobile device or personal computer of basic level. In the current realities of the development of data storage technologies the period of blockchain existence will not exceed 10 years and depends on the capacity of storage devices, whose development falls reasonably behind the growth of blockchain volume.

Usage of blockchain technology might cause serious energy and environmental problems. The blockchain users consume electricity, and the number of the burnt megawatt is regulated 
not because of safety reason or common sense, but only the economy makes sense here: the power can be accumulated as long, as it remains profitable by current blockchain price. In connection with what it is required to evaluate the need of blockchain implementation, to settle restrictions and provide the ability to create blocks only to the trusted participants.

The important step towards removing the institutional barriers in the development of FinTech in Russia became the adoption of the Federal Law dated 31.07.2020 by number $\mathrm{N}$ 259-FZ "About the Digital Financial Assets, Digital Currency and Amendments to Certain Legislative Acts of the Russian Federation" (hereinafter - the Law "About the Digital Assets "), which will come into force on the 1st of January 2020.

This law legalized the definition of "digital assets", "digital currency", "owner of the digital assets" at the state level, as well, it outlined the ranges of the legal mechanism of control over the turnover of digital assets. So, in accordance with the paragraphs 1-2 of the article 5 of this law the operator of the information system, in which the issue of digital financial assets occurs, can be included in the register of information system operators only under condition it is a legal entity, whose personal law is the Russian law, for example, the Russian credit organization having the right to carry out the depository activities and the activities of trade organizer.

The information system operator has the right to perform its activities since it has been included into the register of information system operators, which is maintained by the Bank of Russia. The last oversees the activities of information systems operators, who issues the digital financial assets. All operations with the digital asset are required to be registered into the information system, in which the issue of digital financial assets is performed, in means of fixing the records of their enrollment to the certain physical or legal entity.

\section{Conclusion}

Hereby all transactions with digital financial assets will be personified, the clients engaged in transactions with digital assets will be identified. Meanwhile the Bank of Russia has once again confirmed its status as a mega-regulator and received the power of supervision and monitoring in the area of digital assets turnover. Certainly the system of registers arranged for control and supervision over the turnover of digital financial assets performed by the mega-regulator should ensure the effective fiscal control, as it will make the information about the turnover of digital financial assets accessible to the tax authorities and will withdraw from the shadow turnover the revenues generated by transactions in cryptocurrency.

\section{Acknowledgments}

Adoption of the Law "About the Digital Financial Assets" does not solve the problem of illegal non-personified transactions performed by blockchain technology, as the Internet information and telecommunications network is transboundary in its legal nature, it has a number of technological possibilities to proceed the transactions in impersonalized format (through darknet), which can be performed outside the scope of Russian law (from abroad), but in fact the services are provided on the territory of the Russian Federation. Hereby the analysis of the practice, how the adopted law is executed, will allow to assess the effectiveness of the prescribed rules, which are aimed at the development of the system of national digital assets in the Russian Federation.

\section{References}


1. Kim Y, Choi J, Park Y-J, Yeon J 2016 International Journal of Applied Engineering Research 11(2) 1058-1061

2. Pēteris Zilgalvis 2014 Policy \& Internet 6(4) 377-392

3. Tsai C-Ha, Peng K-Jbcd 2017 Asian Journal of Law and Society 4(1) 109-132

4. Geranio M International Journal of Law and Technology 11:2

5. Aksakov A The Expert Committee on Financial Market Will Define The Legislative Perspectives for The Usage of New Financial Technologies $\mathrm{http} / / /$ komitet212kmdumagovru/

Novostiomiteta/item/14145821?filter\%5Bmonth\%5D=11\&filter\%5Byear\%5D=2017

6. Cuccuro P 2017 International Journal of Law and Information Technology 0 1-17

7. 2017 ESMA The Distributed Ledger Technology Applied to Securities Markets Report https://wwwesmaeuropaeu/sites/default/files/library/dlt_report_-_esma50$1121423017-285 \mathrm{pdf}$

8. Mainelli M and Milne A 2015 Swift Institute Working Paper 7

9. Malinova K and Park A 2016 Market Design with Blockchain Technology Available from SSRN https://ssrncom/abstract $=2785626$

10. http://wwwrbcru/ekb/interview/01/11/2017/59f965499a794761acf47b30

11. Okashin R 2017 Within the Recurrent ICO Hackers Stole the Broadcast in Amount of $\$ 75$ million, Hi-tech https://wwwkasperskyru/blog/good-good-blockchain/18911/ 